\title{
Effect of fly ash on surface tension of few liquids
}

\author{
Shikha Shrivastava ${ }^{1 *}, K$ anti $C_{\text {houby }}{ }^{1}$, J aya Sahu² and M eeta Verma ${ }^{3}$ \\ ${ }^{1}$ Department of Zoology, Government VTY PG Autonomous College, Durg (C.G.), INDIA \\ ${ }^{2}$ National Institute of Technology, Raipur (C.G.), INDIA \\ ${ }^{3}$ Government College of Engineering and Technology, C.G., INDIA \\ *Corresponding author. E-mail:gainbrain@yahoo.co.in
}

\begin{abstract}
Surface tension of different liquids which have an impact on living systems and the changes occurred due to mixing of fly ash was studied, keeping the temperature and amount of fly ash powder, constant. This change is very vital because surface tension is a very vital element for survival in biological world as many animals, and microorganisms survive due to specific surface tension which supports their life on water as larva or adult and even human, because many vital processes like respiration is dependent on surface tension. When yeast cells in aqueous solution, surface tension of $6.65 \times 10^{-2} \mathrm{Newton} /$ Meter at $28^{\circ} \mathrm{C}$ respiration is best but at $5.1 \times 10^{-2} \mathrm{Newton} / \mathrm{meter}$ respiration is inhibited (1953 Carl).
\end{abstract}

Keywords: Surface tension, Capillary rise, Fly ash

\section{INTRODUCTION}

Surface tension is the attraction between molecules (cohesion) at the surface of the liquid, which acts a bit like an elastic skin containing the liquid. It is associated with the amount of energy required to increase its surface per unit area .Surface tension is caused by inter molecular forces at the liquids interface with a gas or a solid. It depends on liquid nature surrounding media, and temperature. Liquids with strong intermolecular forces will have higher values, of surface tension than liquids that have weak intermolecular forces. It is inversely proportion to temperature because reduction of cohesive forces resulting from higher frequency of vibration of liquid molecules at a higher temperature. Zhao (2004) have already presented the molecular simulation of vapour liquid surface tension of Quantum liquids, where $\mathrm{H}_{2}$ acts as a surfactant in $\mathrm{H}_{2} \mathrm{D}_{2}$ mixture. The intermolecular cohesive forces in water molecule are due to hydrogen bonds and these are associated with higher energy levels. Surface tension explains why water can drip slowly from a tap and why mercury gathers into globule on a flat surface. Molecules that are surrounded by others are on average, pulled equally in all directions. At the surface, however, the net force is inwards tending to reduce the surface area. It is called free surface energy. Both are defined at given temperatures, as surface tensions falls with temperature rise. Joel and Mansoori (1998) studied the temperature independent parameter Po for the pure component mixture.

Surface tension is a very important factor in animal kingdom because it necessitates many biological phenomenons as insects walking on the water surface, breathing from water surface, respiration from lungs and many other such things.Even at school level experiments it is seen that as the surface tension decreases with detergent ,as the detergent concentration increases, and lowers the surface tension, deeper the dimple in water is formed by water striders, and at concentration of $.003 \mathrm{M}$ their feet breaks through the water and at $.005 \mathrm{M}$ the water strider is unable to stay above the water.

The importance of surface tension is so important in our daily life that even the cleaning of feaces in newborn has been studied by Dhar (2007) They stated that the feaces have a tendency to stick and scrubbing worsens the status of delicate skin. The emulsion like baby lotion was used to ease the removal by reducing the surface tension and cleaning the debris.

Fly ash is the by product of coal based power plants, which are dumped in the open dykes.Thus the ash from the dykes become a major source of pollution both in air and water in many fold ways as it is sprayed in air by blowing of the wind and thus settling in soil and on the surrounding areas Therefore, the aim of the present study was to know that whether this fly ash also changes the surface tension of water and some other liquid along with other changes in water.

\section{MATERIALS AND METHODS}

The surface tension was studied by capillary rise method. The surface tension of the liquids were studied before and after mixing the fly ash to it, thus the different caused 
by fly ash was Recorded. To measure the height of liquid rise in capillary tube, (least count of microscope is .001.). First the experiments were done with fly ash dissolved indifferent liquids like distilled water, alcohol, ether and tap water.

\section{RESULTS AND DISCUSSION}

The results obtained are given in Table 1 . The radius of the capillary ( $\mathrm{r}$ ) was calculated as $0.048 \mathrm{~cm}$, when density of alcohol was equal to $0.81 \mathrm{gm} / \mathrm{cm}^{3}$ and density of ether was equal to $0.74 \mathrm{gm} / \mathrm{cm}^{3}$. Thus the surface tension for Fly ash solution partially dissolved in- distilled water solution was found to be $6.2046 \times 10^{-2} \mathrm{Newton} / \mathrm{metre}$, alcohol solution- $4.3665 \times 10^{-2} \mathrm{Newton} /$ meter ,ether solution 3.5157 Newton meter and tap water solution $6.5479 \times 10$ ${ }^{2} \mathrm{Newton} / \mathrm{metre}$.

The changes in the surface tension at $20^{\circ} \mathrm{C}$ in different liquids after mixing fly ash are summarized in Table 2. The results indicated that at $20{ }^{\circ} \mathrm{C}$ room temperature, the

Table 1. Readings with fly ash. and it is in the disguise that it will be employed here, second when a hydrophobic object is pressed into the interface between air and water, the water attempts to minimize its contact with object, often at the expense of creating new surface area. As a result, when a water striders presses one of its hydrophobic legs down onto the surface of a pond, a dimple is formed in the waters surface, and the surface is starched. The vertical components of the resulting capillary force resist the downward push of the legs and the water strider is supported (Denny, 2004).

The importance of surface tension for bacteria and fungi was explained by Wosten and Willey, 2000. Filamentous bacteria and fungi form aerial structure from which sexual spores develop, like aerial hyphae. Both groups secrete highly surface-active molecules that lower the surface tension of their aquas environment enabling hyphae to grow in the air. In case of filamentous bacteria, small peptides like sap B and srteptofactin are secreted, while

\begin{tabular}{|c|c|c|c|c|c|c|c|c|}
\hline S.No. & $\begin{array}{c}\text { Fly ash solution } \\
\text { in }\end{array}$ & Reading & p surface & eaker h1 & Readir & $\begin{array}{r}r \text { top men } \\
\text { h2 }\end{array}$ & in capillary & $\begin{array}{l}\text { Rise in capillary } \\
\text { (h2-h1) cm. }\end{array}$ \\
\hline & & MSR & VSR & Total & MSR & VSR & TOTAL & \\
\hline 1. & Distilled water & 2.25 & 30x.001 & 2.280 & 4.90 & $2 x .001$ & 4.902 & 2.622 \\
\hline 2. & Alcohol & 2.25 & 30x.001 & 2.280 & 5.10 & 6x.001 & 5.106 & 2.276 \\
\hline 3. & Ether & 2.25 & 30x.001 & 2.280 & 4.25 & $34 x .001$ & 4.284 & 2.004 \\
\hline 4. & Tap water & 2.25 & 30x.001 & 2.280 & 5.00 & $48 x .001$ & 5.048 & 2.768 \\
\hline
\end{tabular}

day time temperature in December, surface tension of fly ash mixed water is less than the surface tension of water, in the same practical set up and same room temperature, which clearly satisfies the theory of surface tension that is if a solute is less soluble in a liquid then the surface tension of the soluble decreases.

The importance of surface tension in animal world has been demonstrated earlier, where Carl and Campbell (1953) demonstrated the effect of changes in surface tension in aqua solution, due to surface tension active agent Urethane at $28^{\circ} \mathrm{C}$ When the surface tension falls from $6.65 \times 10^{-2} \mathrm{Newton} / \mathrm{meter}$ to $5.1 \times 10^{-2} \mathrm{Newton} / \mathrm{meter}$ it inhibits respiration in yeast.Carl and Campbell (1953) also stated by Denny (2004) where he explained that water striders and water walking spiders used their legs as oars, and capillary dimples formed by each leg acted as oars blade. The resulting hydrodynamics drag produced vortices in water, and the motion of these vortices imparted the necessary fluid momentum. The attraction of one water molecule to another required considerable energy to be expanded to create new area of air water interface.

Pure water has a surface energy of approximately $0.07 \mathrm{Jm}$ 2 (Denny, 2004). The surface energy $\left(\mathrm{J} \mathrm{m}^{-2}\right)$ is dimensionally equivalent to a capillary tension $\left(\mathrm{Nm}^{-1}\right)$ filamentous fungi use proteins known as hydrophobins to decrease the water surface tension. Once escaped in the air, hyphae are covered with hydrophobic film (Wostan and Willey, 2000).

The surface tension of lung dynamics is explained by Silva and Saldiva (1998), where they stated that the lung dynamic behavior is possible due to surface tension. And injury is caused due to increase in surface tension eg. Respiratory distress syndrome. His study was on rats about paraquate intoxication causing pulmonary lesions mainly due to surface active properties, both during inspiration and expiration. Similarly Banerjee and Bellare (2001) studied the respiratory distress syndrome in preterm neonatal and found the reason to be lack of sufficient surfactant in the lungs at the time of birth. Walter Federle (2002) have also studied the mechanics and wet adhesion of pretarsals pads in ants and have stated that hydrophilic liquid is present in between pads. Insect adhesive pads cuticle is a viscoelastic material this process causes energy dissipation and may thus contribute to friction.

Joseph (2002) also stated that floating is the most common interaction between organisms and air water interface, a function of the organisms density (mass by volume) generating an upward bouncy to overcome the 
Table 2. Change in surface tension.

\begin{tabular}{llll}
\hline S.No. & $\begin{array}{l}\text { Surface tension } \\
\text { at } 20^{\circ} \mathrm{C} \text { of }\end{array}$ & $\begin{array}{l}\text { Surface tension } \\
\text { at } 20^{\circ} \mathrm{C} \text { in } \\
\text { Newton/meter }\end{array}$ & $\begin{array}{l}\text { Surface tension } \\
\text { after mixing fly } \\
\text { ash } \\
\text { Newton/meter }\end{array}$ \\
\hline 1. & Tap Water & $7.281 \times 10^{-2}$ & $6.5479 \times 10^{-2}$ \\
2. & Ether & $1.70 \times 10^{-2}$ & $3.5157 \times 10^{-2}$ \\
3. & Alcohol & $2.227 \times 10^{-2}$ & $4.3665 \times 10^{-2}$ \\
\hline
\end{tabular}

pull of gravity (mass by acceleration) surface tension interaction also generates an upward force so negligible in most cases that it is ignored. however a few organisms generate an upward force from surface tension interactions. Insects like water striders can actually walk and jump on the water surface. Vogel (1988) calculated a walk on water index (WOWI) as the ratio of the force holding the organisms pulling the organisms down. To overcome the force generated by gravity (approximately gravity (g) times its volume or length (l) cubed an upward force is generated by organisms contact perimeter $(I)$ with the waters surface times the surface tension (Y). Combining terms after canceling length in the numerators produces a unitters index) the formula being WOWI $=\mathrm{YI} /$ $\mathrm{pl}^{3} \mathrm{~g}=\mathrm{Y} / \mathrm{pl}{ }^{2} \mathrm{~g}$.

Plants have also developed some methods for minimizing the surface tension interaction like cuticular layer of plants is pre adapted for surface tension interaction. Similarly the flowers of Nymphoides by having a conspicuous waxy cuticle (Joseph, 2002). Similarly the surface tension and rheological properties of fluid in deadly carnivorous pitcher plant and its comparison with water has been studied by Laurence Gaume and Yoel Forterre (2007).Thus, the surface tension is an important factor for vital activities. and it was observed that the pollution in water by fly ash changes the surface tension to a considerable limit, thus concluding that it may be fatal for the micro and macro living forms already present in water and it may disturb the water ecosystem.

\section{REFERENCES}

Banerjee R. and Bellare, J. R. (2001). Scoring of surface parameters of physiological relevance to surfactant therapy in respiratory distress syndrome. J A ppl.Physiol., 90: 1447$1454.8750-7587 / 01$.

Carl, Lamanna and Campbell, J. J.R. (1953). Surface activity as the cause of the Anomolous behavior of urethane as an inhibitor of the yeast respiration. J B asm. Org., 65:596600 .

Dhar, Sandipan (2007). New born skin care revisited .Indian J ournal of D ermatology.52 (1): 1-4.

Denny, M. W. (2004). Paradox lost answers and questions about walking on water. J ournal of Experimental Biology, 207: 1601-1606.

Joel, E. and Mansoori, G. A. (1998). Surface tension predictions for liquid mixtures. Al C he. J ournal, 44(10):2324-2332.

Joseph, E. Armstrong (2002). Fringe science-are the collars of Nymphoides flowers adapted for surface tension interaction. American J ournal of B otany, 89:362-365.

Laurence Gaume and Yoel Forterre (2007)"A viscoelastic deadly fluid in carnivorous pitcher plants. Plos one, 2 (11) e1 185.

Silva, M.F.R. and Saldiva, P.H.N. (1998). Paraquat poisoning , an experimental model of dose dependent acute lung injury due to surface dysfunction. Braz. J. M ed. Biol. Res., 31(3): 445-450.

Vogel, S. (1988) Lifes Devices: The physical world of animals and plants.Princeton University press .Princeton USA.pp384.

Walter Federle (2002). An integrative study of insect adhesion: Mechanics and wet adhesion of pre tarsal pads in ants. Integrative and Comparative Biology.42 (6): 1100-1106.

Wosten, H. A.B. and Willey, Joanne M. (2000). Surface active proteins enable microbial aerial hyphae to grow into air. Microbiology, 146: 767-773.

Zhao, Xiongce (2004). Surface tension of Quantum fluids from molecular stimulations. J.C hem. Phys.120: 8707. 